\title{
Article \\ Synthesis, Controlled Release, and Stability on Storage of Chitosan-Thyme Essential Oil Nanocapsules for Food Applications
}

\author{
Ricardo M. González-Reza ${ }^{1,2} \mathbb{D}$, Humberto Hernández-Sánchez ${ }^{1} \mathbb{D}$, David Quintanar-Guerrero ${ }^{3}(\mathbb{D}$, \\ Liliana Alamilla-Beltrán ${ }^{1}$, Yair Cruz-Narváez ${ }^{4}$ and María L. Zambrano-Zaragoza ${ }^{2, *(D)}$ \\ 1 Departamento de Ingeniería Bioquímica, Escuela Nacional de Ciencias Biológicas, \\ Instituto Politécnico Nacional, Unidad Profesional Adolfo López Mateos, \\ Ciudad de México C.P. 07738, Mexico; gonzalez.reza@comunidad.unam.mx (R.M.G.-R.); \\ hhernan1955@yahoo.com (H.H.-S.); lalamilla@ipn.mx (L.A.-B.) \\ 2 Laboratorio de Procesos de Transformación y Tecnologías Emergentes de Alimentos, FES-Cuautitlán, \\ Universidad Nacional Autónoma de México, Cuautitlán Izcalli C.P. 54714, Mexico \\ 3 Laboratorio de Investigación y Posgrado en Tecnología Farmacéutica, FES-Cuautitlán, Universidad Nacional \\ Autónoma de México, Cuautitlán Izcalli C.P. 54740, Mexico; quintana@unam.mx \\ 4 Laboratorio de Posgrado de Operaciones Unitarias, Escuela Superior de Ingeniería Química e \\ Industrias Extractivas, Instituto Politécnico Nacional, Unidad Profesional Adolfo López Mateos, \\ Ciudad de México C.P. 07738, Mexico; ycruzn@ipn.mx \\ check for \\ updates \\ * Correspondence: luz.zambrano@unam.mx; Tel.: +52-5556231999 (ext. 39406)
}

Citation: González-Reza, R.M.; Hernández-Sánchez, H.; Quintanar-Guerrero, D.; Alamilla-Beltrán, L.; Cruz-Narváez, Y.; Zambrano-Zaragoza, M.L. Synthesis, Controlled Release, and Stability on Storage of

Chitosan-Thyme Essential Oil Nanocapsules for Food Applications. Gels 2021, 7, 212. https://doi.org/ $10.3390 /$ gels7040212

Academic Editors: Anja Maria Wagemans and Julia Keppler

Received: 21 October 2021

Accepted: 11 November 2021

Published: 14 November 2021

Publisher's Note: MDPI stays neutral with regard to jurisdictional claims in published maps and institutional affiliations.

Copyright: (c) 2021 by the authors. Licensee MDPI, Basel, Switzerland. This article is an open access article distributed under the terms and conditions of the Creative Commons Attribution (CC BY) license (https:/ / creativecommons.org/licenses/by/ $4.0 /)$.

\begin{abstract}
The nanoencapsulation of thyme essential oil has been greatly important in food science, given its remarkable antioxidant and antimicrobial capacity. However, its analysis in storage has not been established in terms of physical stability, antioxidant capacity, and release studies. In this paper, chitosan-thyme oil nanocapsules were prepared by the ionic gelation method. These were characterized for differential calorimetry, release kinetic, and infrared spectroscopy. The chitosanthyme oil nanocapsules were stored at 4 and $25{ }^{\circ} \mathrm{C}$ for 5 weeks, the changes in particle size, zeta potential, stability (diffuse reflectance), and antioxidant capacity were analyzed and associated with nanocapsules' functionality. The results show that the storage time and temperature significantly modify the particle size (keeping the nano-size throughout the storage), the release of the bioactive was Fickian with $\mathrm{t}^{0.193}$ according to Korsmery \& Peppas and best described by Higuchi model associated with changes in the zeta potential from $8 \mathrm{mV}$ to $-11 \mathrm{mV}$ at $4{ }^{\circ} \mathrm{C}$. The differential scanning calorimetry and infrared spectroscopy results confirm the good integration of the components. The antioxidant capacity revealed a direct relationship with residual oil concentration with a decrease in the ABTS test of $15 \%$ at $4{ }^{\circ} \mathrm{C}$ and $37 \%$ at $25^{\circ} \mathrm{C}$. The residual bioactive content was $77 \%$ at $4{ }^{\circ} \mathrm{C}$ and $62 \%$ at $25{ }^{\circ} \mathrm{C}$, confirming nanoencapsulation effectiveness. The present investigation provides helpful information so that these systems can be applied in food conservation.
\end{abstract}

Keywords: antioxidant capacity; diffuse reflectance; food nanotechnology; emerging technologies

\section{Introduction}

Nanotechnology is one new technology that has emerged to impact food science. This approach focuses on designing, characterizing, producing, and applying systems and components of submicron size $\left(1 \mathrm{~nm}=1 \times 10^{-9} \mathrm{~m}\right)$ to form substances or materials with specific, desirable properties [1]. Polymeric nanoparticles are defined as colloidal particles whose main characteristic is their size: from 1 to $500 \mathrm{~nm}$ [2]. Nanocapsules (NC) are vesicular systems made of polymeric membrane or wall, in which the active molecules are encapsulated [3]. The nanoencapsulation of lipophilic substances has made it possible to provide improved properties to various essential oils, increasing the solubility and protection against light, $\mathrm{pH}$, oxygen, among others [4]. The wall polymer should be 
preferer of natural origin with the advantage of having the best compatibility with food components, and to have the functionality desired in the system, consider the polymer compatibility with the compound to be transported [5].

Chitosan (CS) is a natural polymer obtained from the deacetylation of chitin from the exoskeleton of crustaceans; its use has a significant impact on the environment and has been shown to have significant antimicrobial and antioxidant capacity [6,7]. Among the attractive bioactive substances for use in food processing are essential oils, which have significantly impacted food processing, given their antioxidant and antimicrobial properties [8]. One of the essential oils has captured the attention in food processing is thyme essential oil (TEO); it has shown antimicrobial activity and potent antioxidant capacity due to molecules such as thymol, carvacrol, $\beta$-caryophyllene, $\gamma$-terpinene $\rho$-cymene, among others [9]. However, being an essential oil tends to volatilize easily, and given its lipophilic origin, it has a disadvantage when incorporated in aqueous food matrices.

Nanoencapsulation of TEO has been investigated; however, the stability as time and storage temperature is not yet in sight. Several studies focus on the nanoencapsulation of various essential oils; most of the efforts are focused on finding the optimal preparation conditions as an effect of encapsulating, stabilizing polymers and aspects of antioxidant parameters and antimicrobials [10-12]. In this sense, numerous investigations report the nanoencapsulation of thyme essential oil in chitosan as a polymeric matrix [13-15]. However, the kinetic, antioxidant, and physical stability changes given by storage time and temperature conditions have not been thoroughly evaluated.

The objective of this research was to obtain nano-encapsulated thyme essential oil and study their functionality during the storage at 4 and $25{ }^{\circ} \mathrm{C}$ for 5 weeks in order to establish the application in different food technology areas as edible coatings, active packaging, and development of functional foods. In addition, the functionality was evaluated about the antioxidant capacity, stability, changes in particle size, polydispersity, and zeta potential. Furthermore, the controlled release kinetic was obtained to explain the mechanisms or release of thyme oil from the core of the nanocapsule. Evaluating these parameters is considered of vital importance for applications in food processing and functional food development.

\section{Results and Discussion}

\subsection{Dynamic Light Scattering (DLS) and Electrophoretic Movement ( $\zeta$ )}

Table 1 shows the particle size (PS)from initial characterization on chitosan nanoparticles (CSNP) and chitosan-thyme essential oil nanocapsules (TEO-CSNC); these had unimodal comportment and sizes $<150 \mathrm{~nm}$. The increase in the PS of the TEO-CSNC in contrast to the NE was not significant $(p>0.05)$. The polydispersity index (PDI) of both systems was $\leq 0.3$, indicating a narrow size distribution [16]. The zeta potential ( $\zeta$ ) of the nanoemulsion is negative due to the functional groups in TEO; it becomes positive due to amino groups from chitosan.

Table 1. Characterization by dispersion of laser light and electrophoretic movement of colloidal nanosystems.

\begin{tabular}{cccc}
\hline Sample & PS $(\mathbf{n m})$ & PDI (-) & $\zeta \mathbf{( m V )}$ \\
\hline $\begin{array}{c}\text { Thyme Essential } \\
\text { Oil-Nanoemulsion (TEO-NE) }\end{array}$ & $123 \pm 3$ & $0.34 \pm 0.01$ & $-33 \pm 3.8$ \\
\hline Chistosan Nanoparticles (CSNP) & $115 \pm 3$ & $0.265 \pm 0.03$ & $31.8 \pm 2.8$ \\
\hline $\begin{array}{c}\text { Chitosan-Thyme Essential Oil } \\
\text { Nanocapsules (TEO-CSNC) }\end{array}$ & $139 \pm 1$ & $0.30 \pm 0.01$ & $8.03 \pm 1.1$ \\
\hline
\end{tabular}

\subsection{Encapsulation Efficiency (EE) and Release Kinetics}

The EE of TEO-CSNC was $69.38 \pm 3.15 \%$; this content agrees with the report to thymol and carvacrol components with EE of $46.3 \%$ and $50.9 \%$ in nano-cochleates and $68 \%$ on NC 
of chitosan with TEO $[17,18]$. Figure 1 shows the TEO-CSNC release profile, observing that near to $60 \%$ of TEO was released at $9 \mathrm{~h}$.

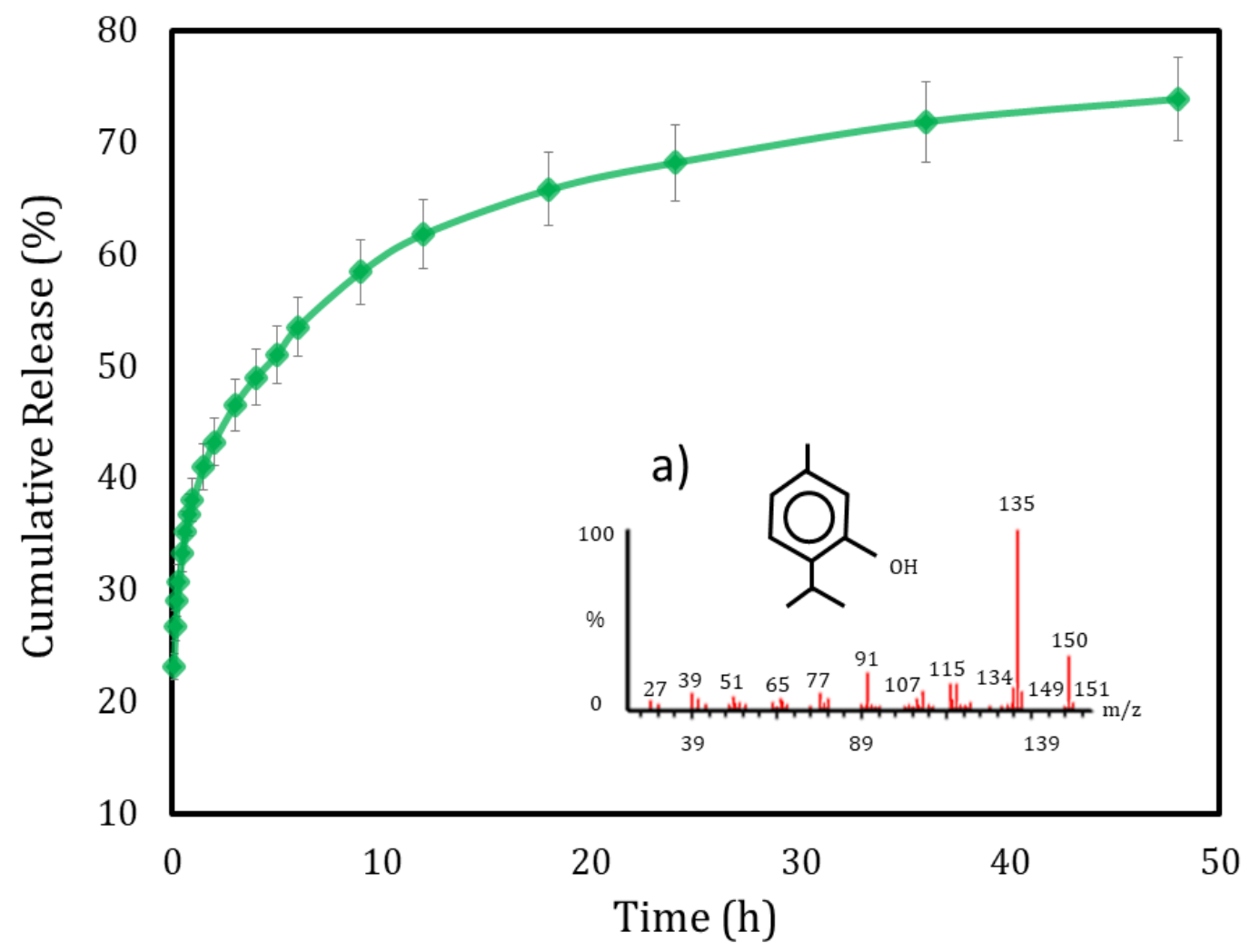

Figure 1. In vitro release profile obtained for the chitosan-thyme nanocapsules, (a) mass spectrum of thymol found in thyme essential oil (majority compound in the sample).

Table 2 shows the constants and coefficients of models of release, and the semiempirical model of Korsmeyer-Peppas with a value of " $\mathrm{n}$ " exponential $<0.5$, suggesting a Fickian release mechanism dependent on the time $t^{0.193}$, which can be explained by TEO diffusion across the membrane, possible swelling, and breaking film [19].

Table 2. Constants and regression coefficients for models applied to the release profile in chitosanthyme nanocapsules.

\begin{tabular}{ccccccccc}
\hline \multicolumn{2}{c}{ Cero-Order } & \multicolumn{2}{c}{ First-Order } & \multicolumn{2}{c}{ Higuchi } & \multicolumn{2}{c}{ Korsmery and Peppas } \\
\hline $\mathbf{K}_{\mathbf{0}}$ & $\mathbf{R}^{\mathbf{2}}$ & $\mathbf{K}_{\mathbf{1}}$ & $\mathbf{R}^{\mathbf{2}}$ & $\mathbf{k}_{\mathbf{H}}$ & $\mathbf{R}^{\mathbf{2}}$ & $\mathbf{n}$ & $\mathbf{k}$ & $\mathbf{R}^{\mathbf{2}}$ \\
\hline 0.097 & 0.667 & 0.089 & 0.746 & 0.124 & 0.968 & 0.193 & 0.97 & 0.991 \\
\hline
\end{tabular}

Surprisingly, good $\mathrm{R}^{2}$ values were obtained for the Higuchi model, which applies to matrixial systems; apparently, a pseudo-stable constant gradient formation does not apply to this capsular system. Thyroid essential oil release studies have reported similar results for chitosan nanocapsules prepared by nanoprecipitation [20]. The equation to describe the release of TEO is:

$$
\text { Oil released }(\%)=37.73 \times \text { Time }(\mathrm{h})^{0.193}
$$

\subsection{Scanning Electron Microscopy (SEM)}

Figure 2 shows the micrographs of the CSNP and TEO-CSNC; these were of a nanometric size and spherical and regular shape with any agglomerations. The sphere structure consists of the polymeric matrix that traps the essential oil. The average size of the TEO- 
CSNC observed by SEM was successfully correlated with the average size obtained by laser light scattering.

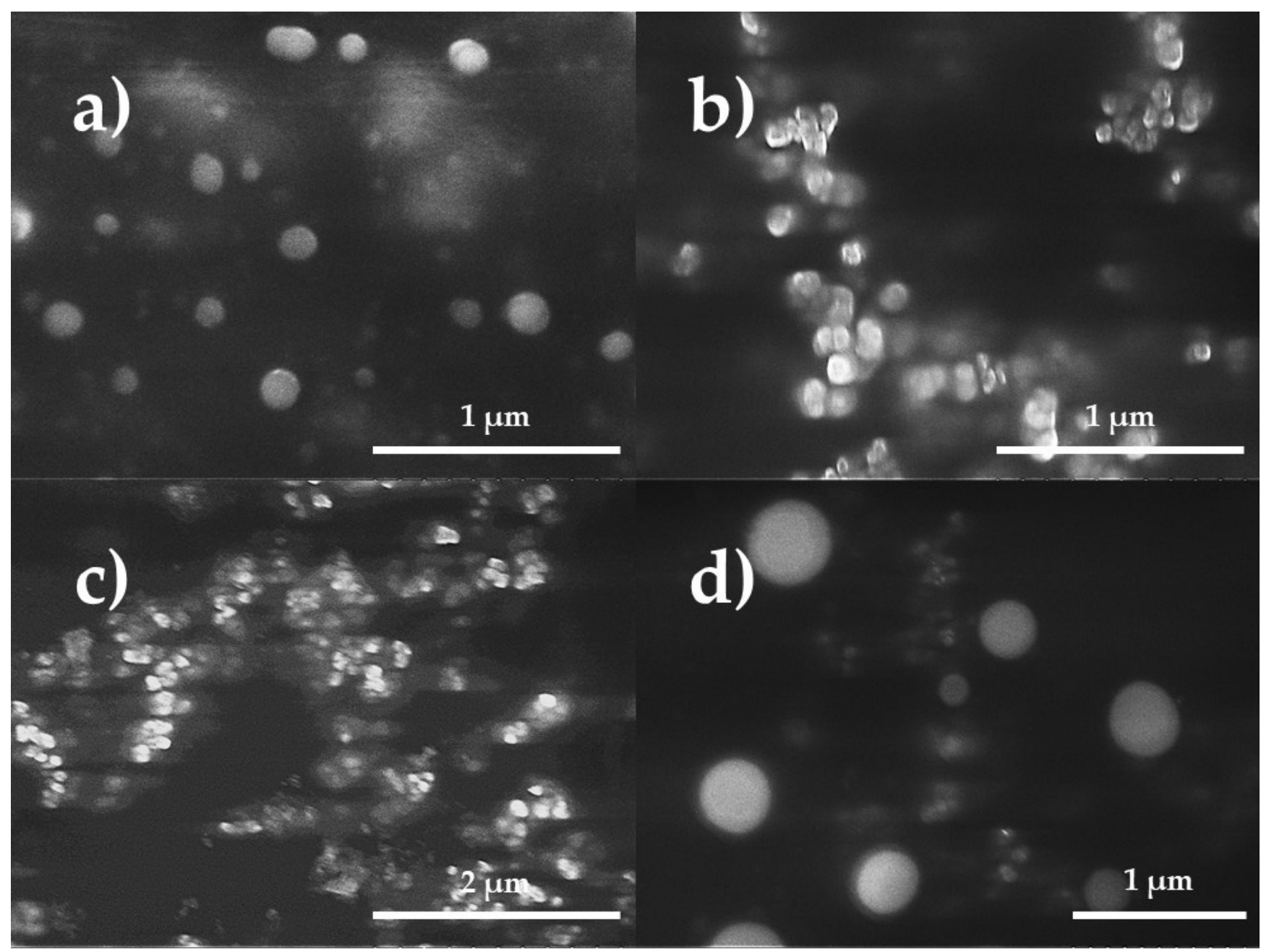

Figure 2. Morphological characterization by SEM of the nanocapsules (a) without charge, (b) loaded with thyme essential oil, (c) loaded with active in week 5 of storage at $25^{\circ} \mathrm{C}$, and (d) loaded with thyme essential oil in week 5 of storage at $4{ }^{\circ} \mathrm{C}$.

\subsection{Differential Scanning Calorimetry (DSC)}

Figure 3 shows the DSC thermograms. Figure 3a shows the heat flow obtained for chitosan, with a melting peak at $141^{\circ} \mathrm{C}$, consistent with studies reported by [6]. No significant changes in heat flow were observed between 20 and $150{ }^{\circ} \mathrm{C}$, and no hydrolysis or oxidation of TEO components was seen $(p>0.05)$ by tripolyphosphate used as a crosslink agent. Figure $3 \mathrm{~d}$ shows the CSNP cross-linking with TPP melting at $127.52{ }^{\circ} \mathrm{C}$ lower than the pure chitosan; TEO-CSNC has a $\Delta \mathrm{H}$ of $82.17 \mathrm{~kJ} / \mathrm{kg}$ Tg of $102.35^{\circ} \mathrm{C}$, indicating physical integration of the components. 

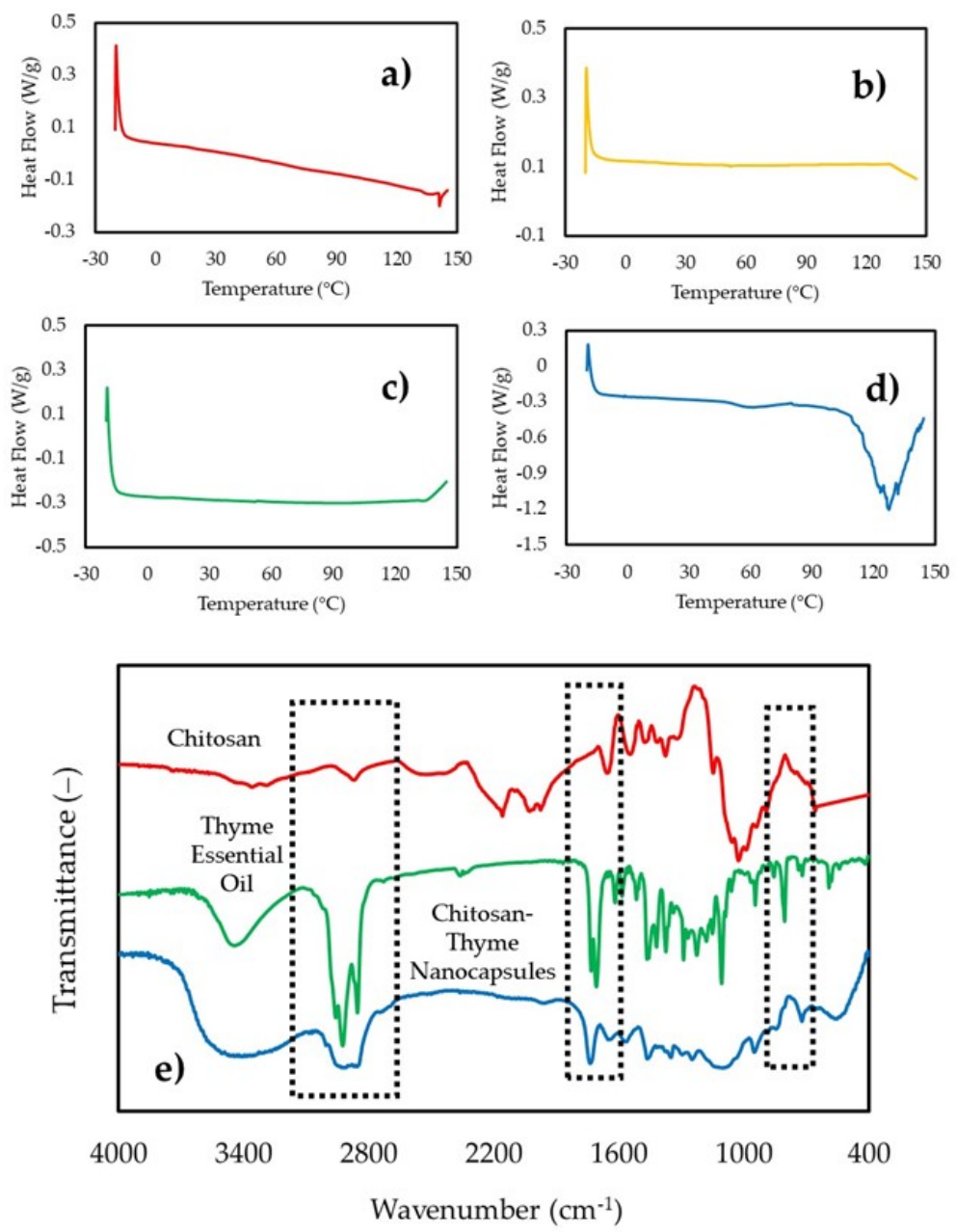

Figure 3. Differential scanning calorimetry for the components of the nanocapsules (a) chitosan, (b) TPP, (c) thyme essential oil, and (d) chitosan-thyme nanocapsules, and (e) infrared spectra of the chitosan nanocapsules obtained by ionic gelation and its components.

\subsection{Infrared Spectroscopy (IR)}

The IR spectroscopy was applied to confirm the cross-linking between the nanostructures of chitosan and the TEO. The IR spectrum of all the components is presented in Figure 3e, showing their typical bands: at $3357 \mathrm{~cm}^{-1}$, the $\mathrm{O}-\mathrm{H}$ stretch superimposed on the $\mathrm{H}$ stretch bands; in $2874 \mathrm{~cm}^{-1}$, the stretching of the $\mathrm{C}-\mathrm{H}$; the amide I band can be found at $1649 \mathrm{~cm}^{-1}$ (C-O stretch of the acetyl group) and the amide II band at $1587 \mathrm{~cm}^{-1}$ (N-H flex). The sharp bands at $1415 \mathrm{~cm}^{-1}, 1374 \mathrm{~cm}^{-1}$, and $1316 \mathrm{~cm}^{-1}$ attributed to the flexion of $\mathrm{CH}_{2}$, the asymmetric flexion of the $\mathrm{CH}$ of the $\mathrm{CH}_{2}$ group, and the amide band III, respectively [13].

Typical absorption peaks of TEO were detected in the nanocapsules at $2926 \mathrm{~cm}^{-1}$ and $2969 \mathrm{~cm}^{-1}$ in all samples. The peaks at $1563 \mathrm{~cm}^{-1}$ and $1466 \mathrm{~cm}^{-1}$ correspond to the vibration $\mathrm{C}=\mathrm{C}$ of the benzene ring in the oil loaded in the nanocapsule. The peaks at $1374 \mathrm{~cm}^{-1}$ and $1110 \mathrm{~cm}^{-1}$ are attributable to the flexion mode $\mathrm{C}-\mathrm{O}-\mathrm{H}$ and the stretching vibration -C-O-, respectively. The peak at $947 \mathrm{~cm}^{-1}$ relates to $\mathrm{C}=\mathrm{C}$ stretching vibration or the flexural vibration of some hydrogen-containing groups, confirming the interaction between chitosan nanostructured and TEO.

\subsection{Dynamic Light Scattering (DLS) during the Storage}

The PS evolution is shown in Table 3; all the samples had PS $\leq 300 \mathrm{~nm}$. The ANOVA revealed a significant effect due to temperature and storage time $(p \leq 0.05)$. The PS increase is explained as a swelling of the polymer matrix, and the TEO was released and left exposed 
very close to the CSNC surface, which correlates directly with the release results discussed above. Studies conducted for the encapsulation of essential oils indicate similar values in the PS $\geq 500 \mathrm{~nm}$ such as cinnamon and clove oil [21,22]. The decrease in PS after 3 weeks results from a greater packing of the polymer chains due to the high number of amino groups in the chitosan responsible for the interaction with TEO [21].

Table 3. Evolution of PS, PDI, $\zeta$ and residual content of TEO-CSNC during storage at 4 and $25^{\circ} \mathrm{C}$.

\begin{tabular}{|c|c|c|c|c|c|c|c|c|}
\hline \multirow[b]{2}{*}{ Week } & \multicolumn{4}{|c|}{$4^{\circ} \mathrm{C}$} & \multicolumn{4}{|c|}{$25^{\circ} \mathrm{C}$} \\
\hline & $\begin{array}{c}\text { PS } \\
(\mathrm{nm})\end{array}$ & $\begin{array}{c}\text { PDI } \\
(-)\end{array}$ & $\underset{(\mathrm{mV})}{\zeta}$ & $\begin{array}{l}\text { RC } \\
(\%)\end{array}$ & $\begin{array}{c}\text { PS } \\
(\mathrm{nm})\end{array}$ & $\begin{array}{c}\text { PDI } \\
(-)\end{array}$ & $\underset{(\mathrm{mV})}{\zeta}$ & $\begin{array}{l}\text { RC } \\
(\%)\end{array}$ \\
\hline 0 & $139 \pm 1^{a}$ & $0.30 \pm 0.01^{a}$ & $8.0 \pm 1.3^{a}$ & $99.2 \pm 0.7^{\mathrm{a}}$ & $139 \pm 1^{a}$ & $0.30 \pm 0.01^{a}$ & $8.0 \pm 1.3^{a}$ & $99.2 \pm 0.7^{a}$ \\
\hline 1 & $139 \pm 4^{\mathrm{a}}$ & $0.30 \pm 0.04^{\mathrm{a}}$ & $10.8 \pm 1.6^{b}$ & $89.4 \pm 2.8^{b}$ & $157 \pm 1^{b}$ & $0.27 \pm 0.03^{a}$ & $20.0 \pm 1.0^{b}$ & $80.1 \pm 1.7^{b}$ \\
\hline 2 & $162 \pm 3^{b}$ & $0.32 \pm 0.02^{\mathrm{a}}$ & $16.6 \pm 0.5^{c}$ & $79.9 \pm 1.1^{c}$ & $185 \pm 2^{c}$ & $0.32 \pm 0.01^{\mathrm{a}}$ & $16.6 \pm 0.7^{c}$ & $76.6 \pm 1.4^{c}$ \\
\hline 3 & $180 \pm 7^{c}$ & $0.49 \pm 0.01^{b}$ & $17.0 \pm 0.9^{\mathrm{d}}$ & $76.7 \pm 1.2^{c}$ & $284 \pm 5^{d}$ & $0.34 \pm 0.03^{a}$ & $18.1 \pm 0.3^{\mathrm{d}}$ & $77.1 \pm 0.8^{c}$ \\
\hline 4 & $182 \pm 7^{c}$ & $0.47 \pm 0.01^{b}$ & $6.8 \pm 0.3^{\mathrm{e}}$ & $78.5 \pm 4.1^{c}$ & $242 \pm 2^{e}$ & $0.42 \pm 0.01^{b}$ & $17.6 \pm 0.8^{d}$ & $73.6 \pm 2.4^{\mathrm{c}}$ \\
\hline 5 & $161 \pm 3^{b}$ & $0.50 \pm 0.04^{b}$ & $-11.1 \pm 0.3^{f}$ & $77.3 \pm 5.2^{c}$ & $193 \pm 2^{f}$ & $0.48 \pm 0.02^{c}$ & $16.3 \pm 0.5^{\mathrm{e}}$ & $62.0 \pm 3.6^{d}$ \\
\hline
\end{tabular}

PS = particle size; $\mathrm{PDI}=$ polydispersity index $\zeta \zeta=$ zeta potential; $\mathrm{RC}=$ residual TEO content. Different letters to the left represent statistically significant differences $(p>0.05)$.

Table 3 shows the evolution in the TEO-CSNC on PDI during storage, observing the significant effect of the storage $(p \leq 0.05)$ the aggregation phenomena can increase. However, the principals' PDI changes were present at 3 and 4 weeks in samples at 4 and $25^{\circ} \mathrm{C}$, respectively, When the TEO was released. However, there is no research on CSNC behavior during storage and the greater stability at $25^{\circ} \mathrm{C}$ attributing to the relaxation of the polymer chains, which make the components of the system not had large aggregation of particles.

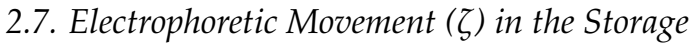

Table 3 shows the $\zeta$ evolution of CSNC-TEO. The zeta potential obtained for the chitosan nanocapsules without TEO was $31.8 \pm 2.8 \mathrm{mV}$. The $\zeta$ reduction was associated with the fact that the positively charged amino groups bind to the $\mathrm{OH}$ groups of the thymol and the carvacrol contained in the thyme essential oil. The increase observed in the average size, together with the decrease in zeta potential, have also been reported after loading carvacrol, eugenol, and lime essential oils, and ellagic acid into chitosan nanoparticles [21]. Similar values have been reported for eugenol-chitosan nanoemulsions produced by ultrasound-mediated emulsification [23]. After 3 weeks at $4{ }^{\circ} \mathrm{C}$ the $\zeta$ decreases and shows a statistically significant difference $(p \leq 0.05)$. This compartment is explained by the low availability of $\mathrm{NH}_{2}$ groups from chitosan; since these interact with the thyme oil release across the $\mathrm{OH}$ groups present in the phenols and aromatic compounds [20]. The functional groups that interact are visible in the infrared presented in Figure 3.

\subsection{Thyme Essential Oil Residual Content}

The TEO concentration is shown in Table 3; the ANOVA evidences a statistically significant effect of storage time and temperature $(p \leq 0.05)$. A significant decrease occurred in the samples stored at $25^{\circ} \mathrm{C}$ in the first week of storage, as they presented losses of the active agent of approximately $20 \%$. This can be explained by the fact that the terpenes of the essential oils are volatile compounds, so the effect of temperature was a determining factor in their residual concentration [8]. Stabilization of the thyme essential oil concentration occurred in storage at $4{ }^{\circ} \mathrm{C}(\sim 75 \%)$ from week 2 until the end of storage, in contrast to the result of $\sim 60 \%$ obtained at $25{ }^{\circ} \mathrm{C}$. Numerous studies mention the effect of temperature on thermolabile compounds during storage. However, the polymer structure affects the properties of bioactive agents including the antioxidant capacity discussed below. 


\subsection{Antioxidant Capacity}

\subsubsection{ABTS}

The antioxidant activity determined by ABTS of the TEO was $2238 \mu \mathrm{mol}$ Eq ascorbic $\mathrm{acid} / \mathrm{g}$ of TEO that contrasts to that obtained in the chitosan TEO-CSNC, which was 4104 $\mu \mathrm{mol}$ Eq ascorbic acid/g of TEO-CSNC. This difference is because chitosan has an excellent antioxidant capacity $[7,24]$, denoted by the significant effect of chitosan that promotes ABTS oxidation due to its ability to donate electrons. Figure 4a shows the ABTS, which is directly proportional to the total active agent concentration in the samples analyzed as a function of time.

The antioxidant capacity decreases $16 \%$ in the third week at $4{ }^{\circ} \mathrm{C}$ no further degradation until the end of storage ( $3300 \mu \mathrm{mol} \mathrm{Eq}$ ascorbic acid/g of TEO-CSNC); so, under this temperature, it is possible to maintain the antioxidant capacity and to have functionality for application in food preservation. The TEO-CSNC at $25^{\circ} \mathrm{C}$ decreases the ABTS by $\sim 50 \%$ at the end of storage ( 2582 $\mu \mathrm{mol} \mathrm{Eq} \mathrm{ascorbic} \mathrm{acid/g} \mathrm{of} \mathrm{TEO-CSNC)}(p \leq 0.05)$. Attributable to the temperature, at $25^{\circ} \mathrm{C}$ the polymer chains modify the permeability and facilitate TEO release, that oxidized quickly under the environmental condition; however, its application in food preservation is viable until the third week else it loses $18 \%$ of its antioxidant capacity. A similar phenomenon was reported by [25], showing that the activity of sweeping ABTS radicals from chitosan films with incorporated ferulic acid has a time-dependent behavior.

\subsubsection{DPPH}

Figure $4 \mathrm{~b}$ shows the antioxidant activity by DPPH. The antioxidant activity of TEO was different $(p \leq 0.05)$ from that obtained for TEO-CSNC with a value of $274.74 \mu \mathrm{mol} \mathrm{Eq}$ ascorbic acid/g of oil $176.9 \mu \mathrm{mol} \mathrm{Eq}$ ascorbic acid/g of TEO-CSNC, respectively. A significant decrease $(p \leq 0.05)$ occurred in the first week of temperature-independent storage. Subsequently, no statistically significant differences were found given by temperature or storage time $(p>0.05)(\sim 130 \mu \mathrm{mol} \mathrm{Eq}$ ascorbic acid/g of TEO-CSNC); this may be the result of the DPPH radical being removed by the Maillard reaction with its reaction products by developing reductants that terminate the free radicals. Therefore, the Maillard reaction between the hydroxyl group and the $\mathrm{OH}$ groups of the TEO molecules is more effective in capturing DPPH radicals than the amino groups of chitosan, as described in detailed experiments [26] for chitosan-ascorbate nanoparticles. The results of the ABTS trial showed congruence with the DPPH method. The increase in TEO concentration has progressively eliminated the ABTS radical determined by ABTS discoloration and the DPPH radical.

\subsubsection{FRAP}

Unlike DPPH and ABTS, FRAP measures the reducing (chelating) power of the samples. The results obtained are shown in Figure $4 \mathrm{c}$. The antioxidant capacity by FRAP of TEO was different $(p \leq 0.05)$ from the TEO-CSNC with $946.04 \mu \mathrm{mol} \mathrm{Eq}$ ascorbic acid/g of TEO and $746.8 \mu \mathrm{mol} \mathrm{Eq}$ ascorbic acid/g TEO-CSNC, respectively. There was no statistically significant difference in the FRAP-values until the third week at $4{ }^{\circ} \mathrm{C}$ and the second week at $25^{\circ} \mathrm{C}$ after having an increase in antioxidant capacity by FRAP $(p \leq 0.05)$, however at $25^{\circ} \mathrm{C}$, in the end, it showed a decrease due to the oxidation of TEO which correlates directly with the release profiles previously analyzed, in addition to the $\zeta$ values determined for the last weeks of storage at $4{ }^{\circ} \mathrm{C}$. Studies conducted by [27] for films composed of chitosan and phenolic extracts showed that they attribute the values of antioxidant capacity to the release of bioactive compounds, which coincides with that obtained in this study.

\subsection{Diffuse Reflectance}

Figures 5 and 6 show the changes in the transmission and backscattering profiles of the TEO-CSNC at 25 and $4{ }^{\circ} \mathrm{C}$, respectively. 

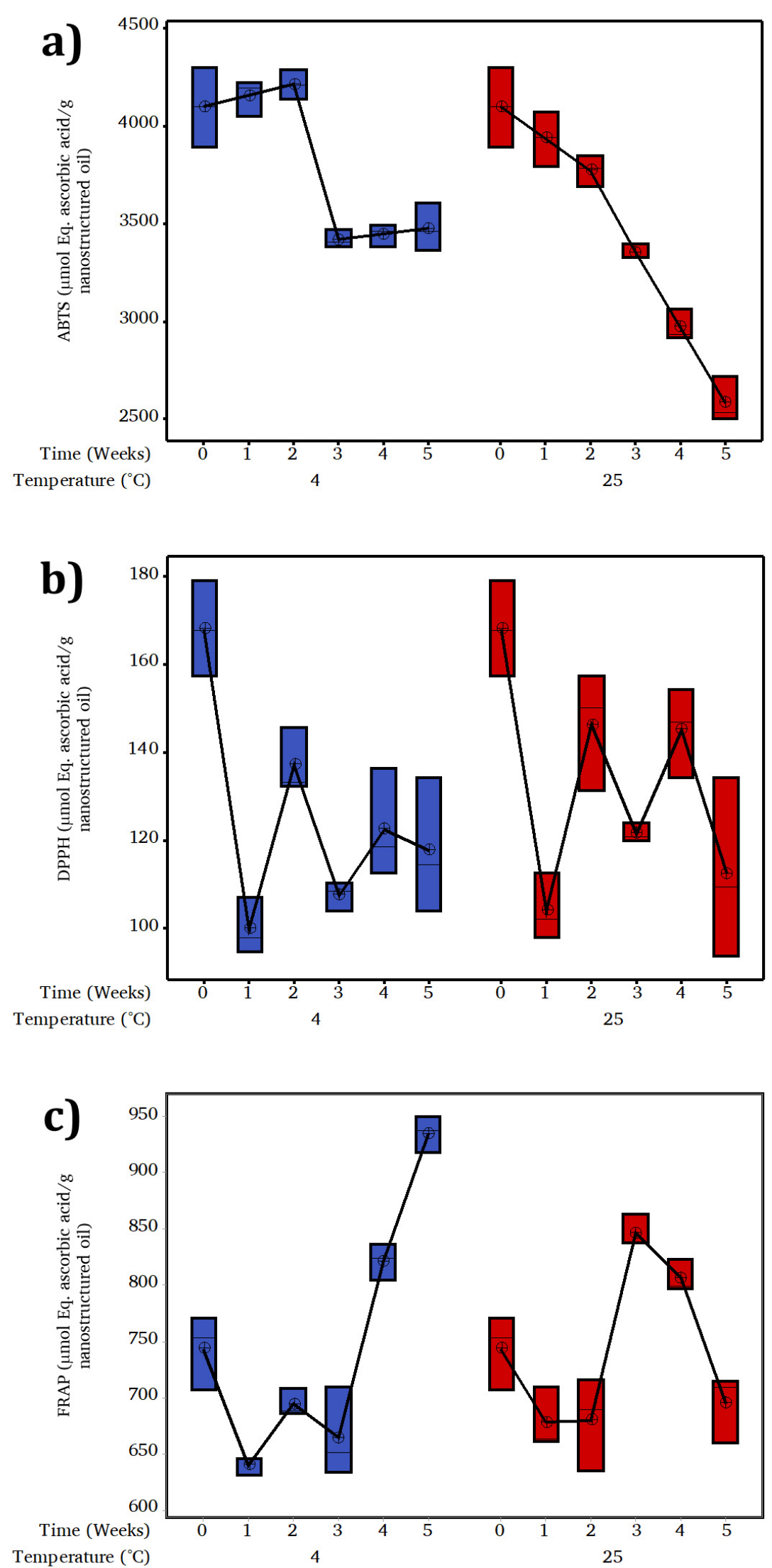

Figure 4. Evolution of antioxidant capacity by: (a) ABTS; (b) DPPH; and (c) FRAP of chitosan-thyme nanocapsules onto storage at 4 and $25^{\circ} \mathrm{C}$. 


\section{Transmission}

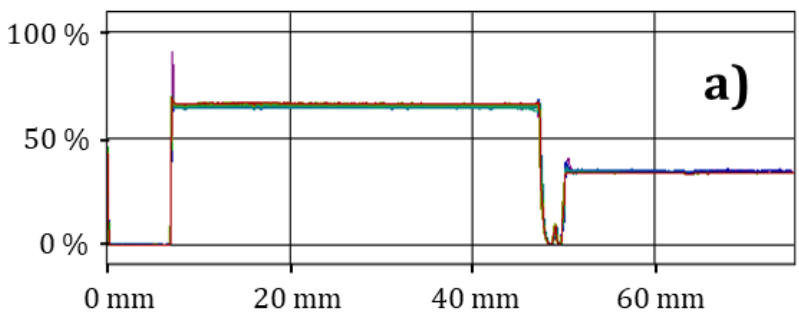

Height of suspension

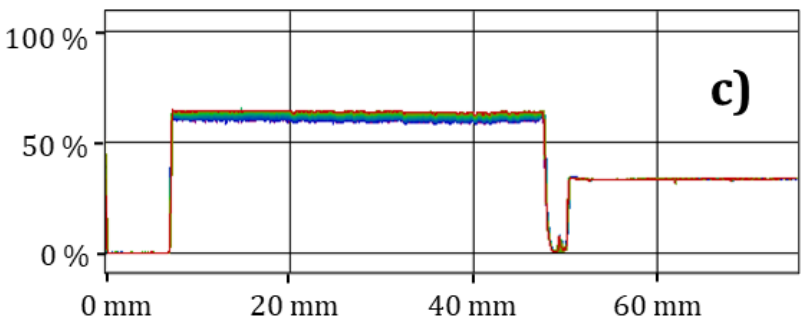

Height of suspension

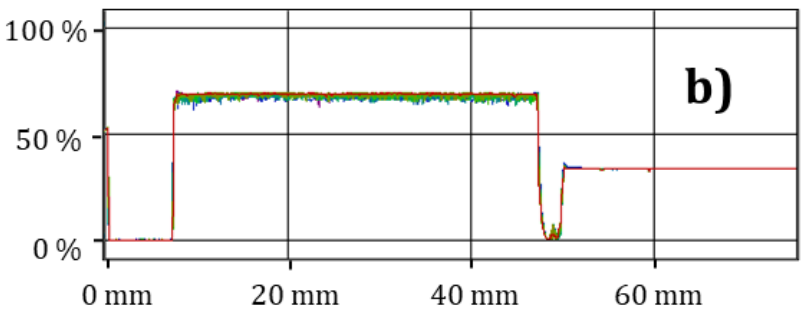

Time (h)

Height of suspension

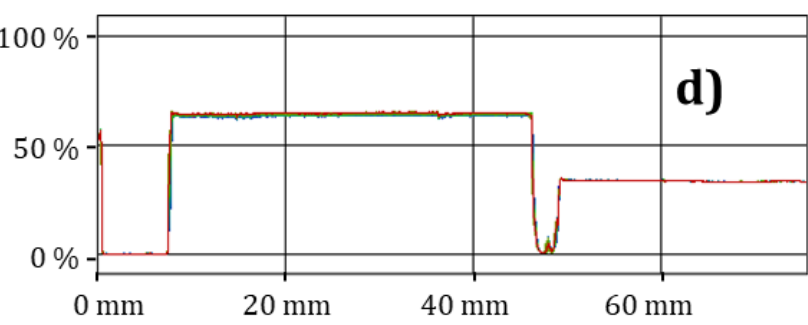

Height of suspension

\section{Back Scattering}

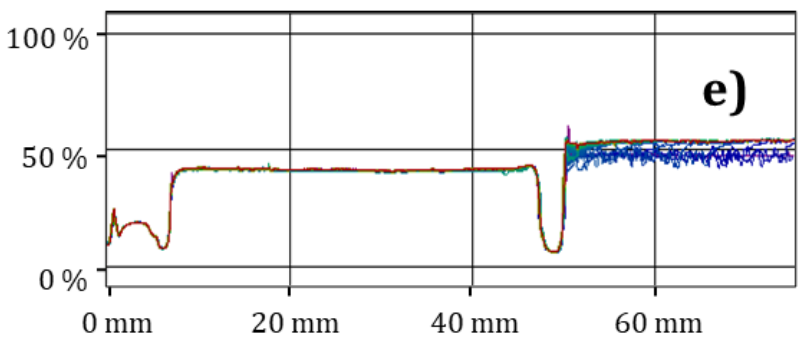

Height of suspension

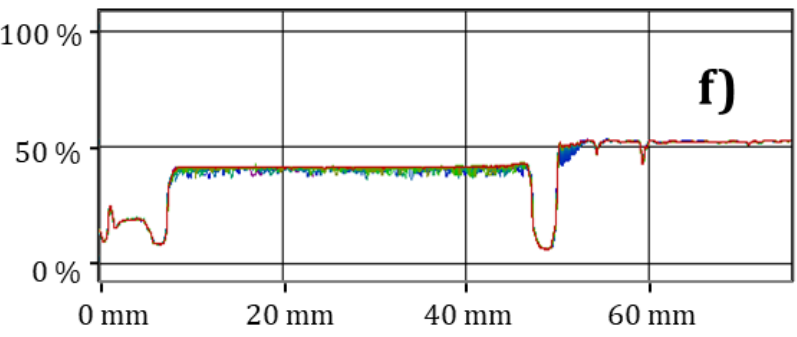

Height of suspension

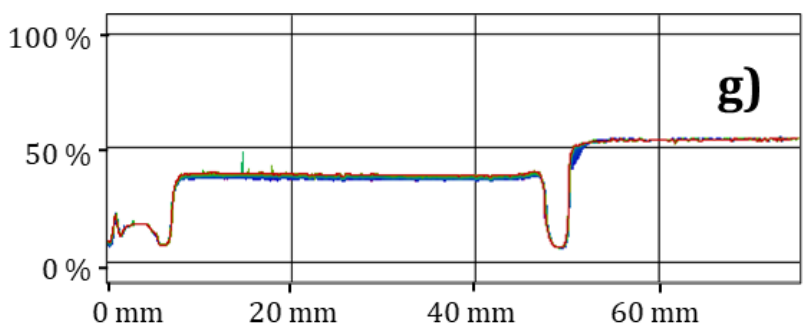

Height of suspension

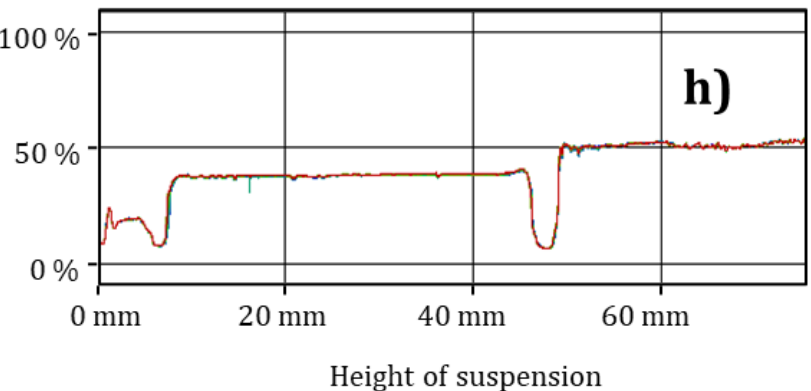

Figure 5. Transmission and backscatter profiles of nanocapsules stored at $25^{\circ} \mathrm{C}$. (a,e) initial, (b,f) week 1 , (c,g) week 3 $(\mathbf{d}, \mathbf{h})$ week 5 .

The samples do not have statistically significant differences $(p>0.05)$ in terms of transmission, backscatter profiles, and maximum thickness given by storage time and temperature. A slight destabilization was found at the end of storage at $4{ }^{\circ} \mathrm{C}$ (Figure $6 \mathrm{~d}, \mathrm{~h}$ ), correlating with TEO release and changes in the $\zeta$. However, this was not significant $(p>0.05)$. It was attributed to the fact that the released oil still retained its nanometric size and was stabilized through charges in the aqueous medium. 


\section{Transmission}
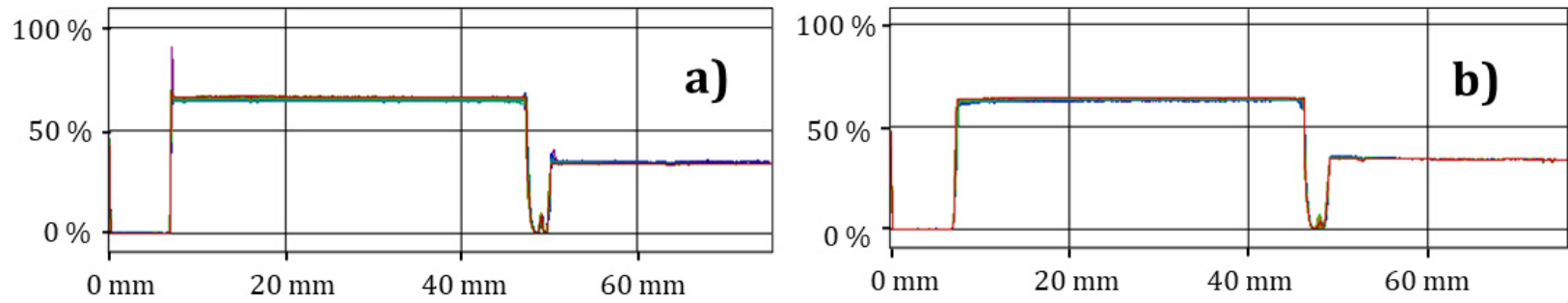

Height of suspension

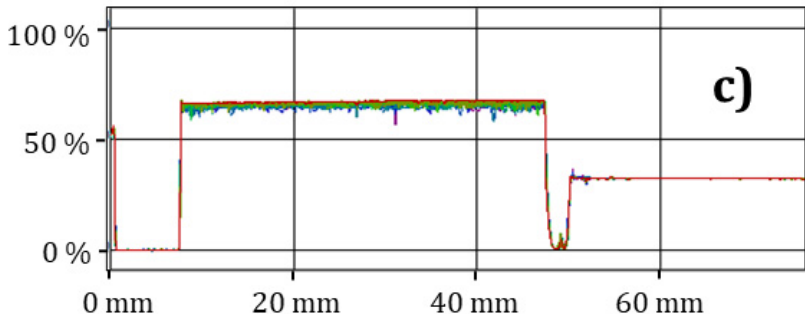

Height of suspension

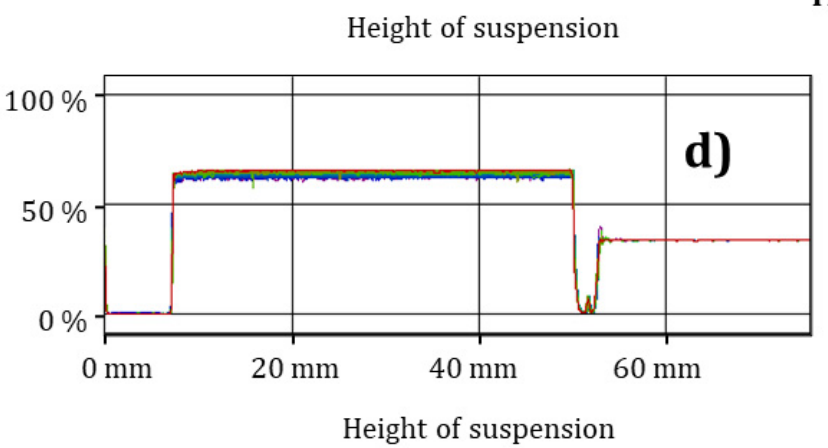

Time (h)
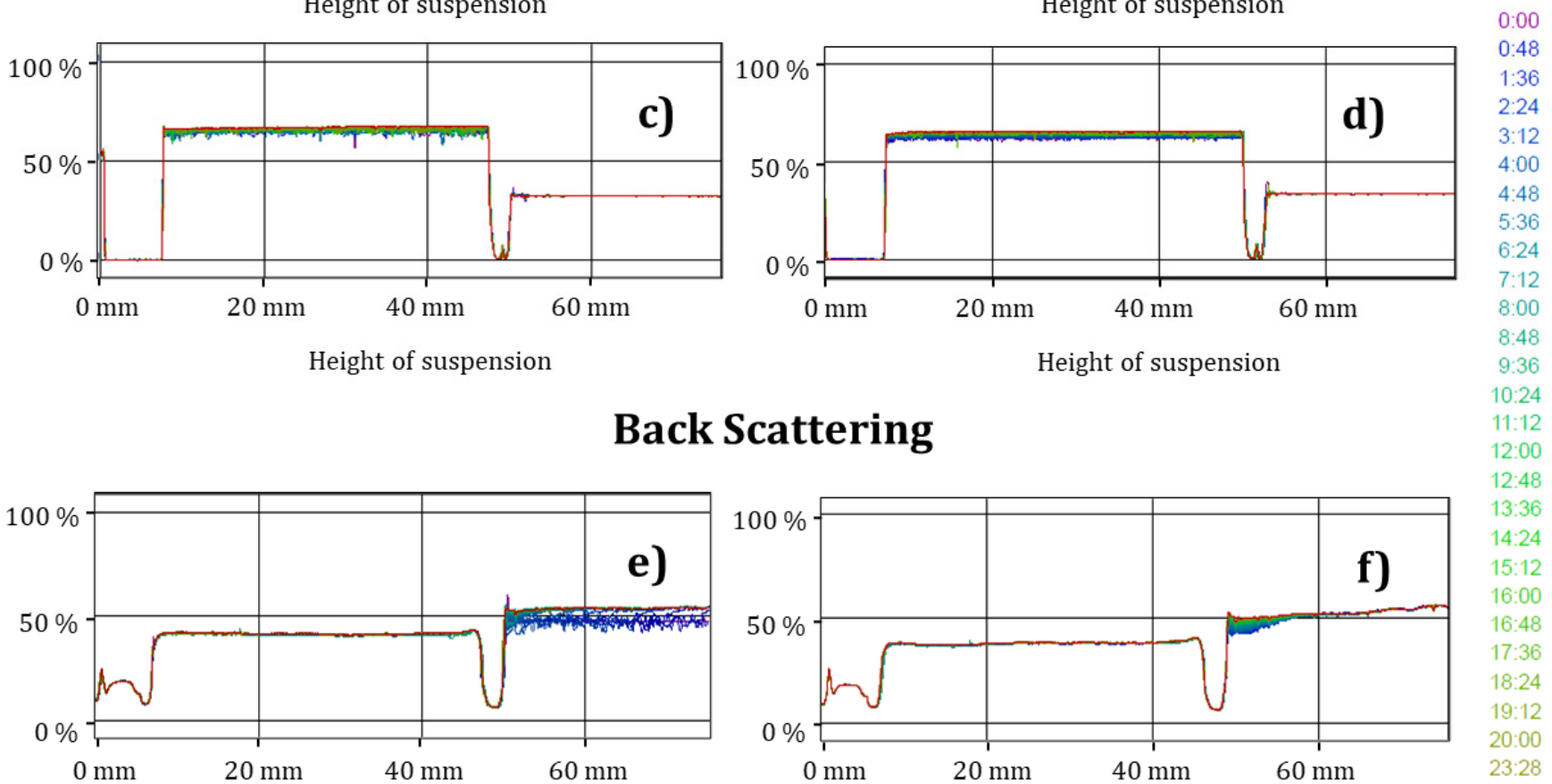

Height of suspension
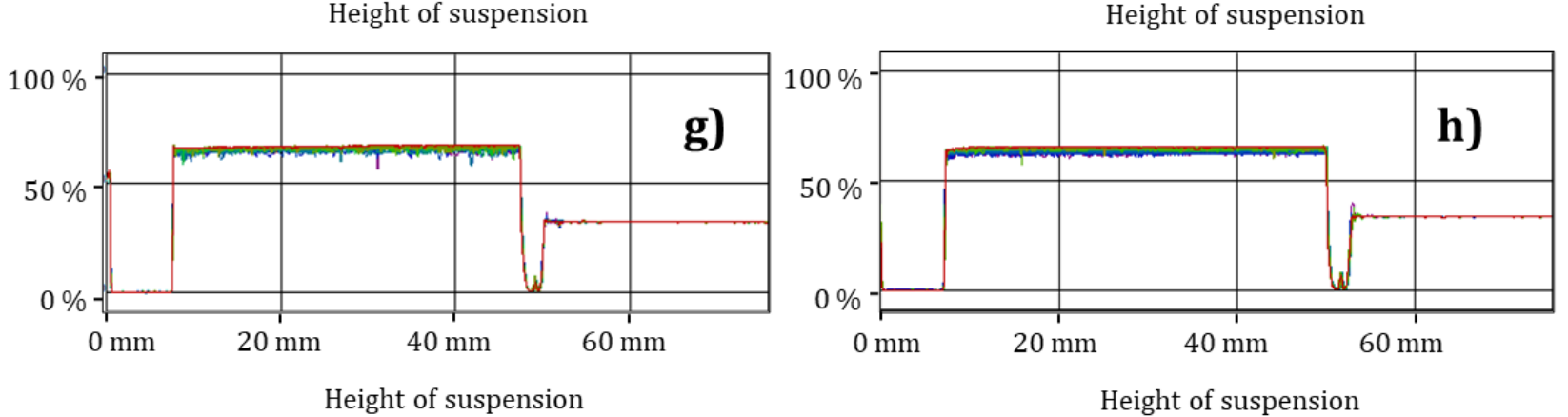

Figure 6. Transmission and backscatter profiles of nanocapsules stored at $4{ }^{\circ} \mathrm{C}$. (a,e) initial, $(\mathbf{b}, \mathbf{f})$ week 1 , (c,g) week 3 , $(\mathrm{d}, \mathrm{h})$ week 5.

\section{Materials and Methods}

\subsection{Materials}

Thyme essential oil $\left(\rho=0.917 \mathrm{~g} / \mathrm{cm}^{3}\right.$ at $25^{\circ} \mathrm{C}$ ) from Sigma-Aldrich ${ }^{\circledR}$ (St. Louis, MO, USA) (Lot: MKCF4333) is used to form the oil nucleus. Chitosan (MW = 50-190 kDa, $\mu=20-300 \mathrm{cP}$ in $\mathrm{CH}_{3} \mathrm{COOH}$ solution $(1 \mathrm{~g} / \mathrm{L})$ at $\left.25^{\circ} \mathrm{C}\right)$ (Lot: STBH6262) as the encapsulating polymer, Tween ${ }^{\circledR} 80$ and Span ${ }^{\circledR} 80$ (Lot: MKBV4425V) were purchased from Sigma Aldrich ${ }^{\circledR}$. The distilled water was Milli- $\mathrm{Q}^{\circledR}$ grade (Millipore Corporation, Bedford, MA, USA). ABTS (2,2'-azino-bis- (3-ethylbenzthiazoline)-6-sulfonic acid) (Lot: SLBD8908V), DPPH (2,2-diphenyl-1-picrylhydracil) (Lot: STBG9431), FRAP (2,4,6-tri (2-pyridyl)-s-triazine) 
(Lot: BCBW6989) were purchased from Sigma Aldrich ${ }^{\circledR}$ (St. Louis, MO, USA). Ascorbic acid $\left(\mathrm{C}_{6} \mathrm{H}_{8} \mathrm{O}_{6}\right)$ (Lot: A0616289), potassium persulfate $\left(\mathrm{K}_{2} \mathrm{~S}_{2} \mathrm{O}_{8}\right)$ (Lot: M1010511), potassium dihydrogen phosphate $\left(\mathrm{KH}_{2} \mathrm{PO}_{4}\right)$ (Lot: M0918575), dipotassium hydrogen phosphate $\left(\mathrm{KH}_{2} \mathrm{PO}_{4}\right)$ (Lot: M1014575), and glacial acetic acid $\left(\mathrm{CH}_{3} \mathrm{COOH}\right)$ (Lot: A0414235) were purchased from Meyer ${ }^{\circledR}$ (Reactivos Química Meyer, Ciudad de México, México). Cyclohexane $\left(\mathrm{C}_{6} \mathrm{H}_{12}\right)$ and methanol $\left(\mathrm{CH}_{3} \mathrm{OH}\right)($ Lot: 824333$)$ were purchased from Fermont ${ }^{\circledR}$ (Productos Químicos Monterrey, México).

\subsection{Nanoemulsion Preparation (NE)}

The thyme essential oil-nanoemulsion (TEO-NE) was prepared by the ultra-high agitation method [28]. Briefly, $5 \mathrm{~g} / \mathrm{L}$ of $\operatorname{Span}^{\circledR} 80$ and $2 \mathrm{~g} / \mathrm{L}$ of TEO were added to the dispersed phase. The continuous phase was composed of $10 \mathrm{~g} / \mathrm{L}$ Tween ${ }^{\circledR} 80$. The NE was obtained in 3 cycles of 5 min at $1047.2 \mathrm{~s}^{-1}$ of ultra-high agitation and resting intervals of $5 \mathrm{~min}$ between cycles, using a rotor/stator homogenizer (Ultra-Turrax T25, IKA ${ }^{\circledR}$, Wilmington, DC, USA) at $25{ }^{\circ} \mathrm{C}$. This NE was the basis for the formation of chitosan nanocapsules.

\subsection{Chitosan Nanocapsules Preparation (CSNC)}

The CSNC were prepared by the ionic gelation method. Briefly, $50 \mathrm{~mL}$ of the NE prepared above was added to glacial acetic acid $(1 \mathrm{~g} / \mathrm{L})$ and chitosan $(3 \mathrm{~g} / \mathrm{L})$ to prepare a dispersion by magnetic stirring at $78.54 \mathrm{~s}^{-1}$ for $2 \mathrm{~h}$. Once the dispersion was completely homogeneous, it was maintained with magnetic stirring at $78.54 \mathrm{~s}^{-1}$ at $25^{\circ} \mathrm{C}$, and $20 \mathrm{~mL}$ of sodium tripolyphosphate $(3 \mathrm{~g} / \mathrm{L})$ solution was added dropwise $(1 \mathrm{~mL} / \mathrm{min})$ using a syringe pump (NE-1000, New Era Pump Systems Inc. Farmingdale, New York, NY, USA). Once the components were mixed, ultrasonication was applied for 3 min utilizing an ultrasonic processor (Hielscher Ultrasonics, UP200Ht, Teltow, Germany) with a titanium sonotrode (Hielscher Ultrasonics, S26d14, Teltow, Germany) with a diameter of $14 \mathrm{~mm}$ $\left(154 \mathrm{~mm}^{2}\right), 80 \mathrm{~mm}$ in length and an external thread, at a power of $50 \mathrm{~W}$ later to adjust the $\mathrm{pH}$ of the mixture at 5 with $\mathrm{NaOH}(0.2 \mathrm{~N})$. Once obtained, the samples are stored in $100 \mathrm{~mL}$ high-density polyethylene terephthalate containers at 4 and $25^{\circ} \mathrm{C}$ for analysis every 7 days for 5 weeks. Chitosan nanoparticles (CSNP) were prepared in the same form without TEO$\mathrm{NE}$ and used as a comparison test.

\subsection{Dynamic Light Scattering (DLS) and Electrophoretic Movement ( $\zeta)$}

The particle size (PS) and the polydispersity index (PDI) were determined by laserscattering using a Z-sizer 4 (Zetasizer Nano Series, Malvern Ltd., Enigma Business Park, Grovewood Road, UK) at a $90^{\circ}$ angle, for the nanosystems. The zeta potential (C) was determined by electrophoretic mobility normalized with standard polystyrene dispersion $(\zeta=-55 \mathrm{mV}$ ) using a Z-sizer Nano ZS90 (Malvern Ltd., Enigma Business Park, Grovewood Road, UK). For both the determinations, the samples were diluted with Milli ${ }^{\circledR} \mathrm{Q}$ distilled water in a ratio of 1:20. The measurements were made at $25^{\circ} \mathrm{C}$ in triplicate [29].

\subsection{Encapsulation Efficiency (EE) and Release Kinetics}

The encapsulation efficiency (EE) was determined by spectrophotometry using a Genesys $10 \mathrm{~s}$ UV/VIS spectrophotometer (Thermo Scientific, Waltham, Massachusetts, USA) at $275 \mathrm{~nm}$ separating the quantity not encapsulated by centrifugation (Hermle Z323K, Labortechnik GMBH, Wehingen, Germany) for $20 \mathrm{~min}$ at $4{ }^{\circ} \mathrm{C}$ at $18,000 \times g$. The release studies are carried out according to the methodology proposed by [19]. Briefly, TEO-CSNC was lyophilized, and the powder resuspended in $1 \mathrm{~g} / \mathrm{L}$ of cyclohexane after centrifugation at $18,000 \times g$ for $20 \mathrm{~min}$ at $4{ }^{\circ} \mathrm{C}$, and the release profiles were obtained to quantify the thyme oil expelled from nanocapsules in the supernatant. The volume lost periodically for each measurement was replaced. The absorbance was measured in a Genesys $10 \mathrm{~s}$ UV/VIS spectrophotometer (Thermo Scientific, Waltham, MA, USA), and the concentrations of active release were obtained with respect to the TEO calibration curve at $275 \mathrm{~nm}$. The 
controls were made by centrifuging $1 \mathrm{~mL}$ of free polymer in the release medium. All release experiments of the nanocapsules were performed in triplicate for $48 \mathrm{~h}$ at $25^{\circ} \mathrm{C}$ [30].

\subsection{Scanning Electron Microscopy (SEM)}

The TEO-CSNC and CSNP were purified by three centrifugations at $18,000 \times g$ for 20 min at $4{ }^{\circ} \mathrm{C}$ (Hermle Z323K, Labortechnik GmbH, Wehingen, Germany). Then a drop of the concentrated suspension was spread on a glass surface and allowed to dry. Electron channeling contrast images were taken using a high-resolution cold field emission scanning electron microscope (Hitachi, SU-8230, Tokyo, Japan), with a BSE + BSE (U) detector, an acceleration voltage of $2.5 \mathrm{kV}$, average deceleration mode with a voltage of $1.5 \mathrm{kV}$. The emission current was $5 \mu \mathrm{A}$, and the working distance $=3.7 \mathrm{~mm}$.

\subsection{Differential Scanning Calorimetry (DSC)}

The TEO-CSNC and individual components were evaluated using a differential scanning calorimeter (TA Instruments, DSC Discovery, New Castle, Delaware, USA) to obtain thermal comportment according methodology proposed by [30]. All samples ( $3 \mathrm{mg}$ ) were placed in hermetically sealed aluminum containers and placed in the chamber of the equipment at room temperature. Total of $40 \mathrm{~mL} / \mathrm{L}$ flow of $\mathrm{N}_{2}$ gas was used in the purge line to control the local environment around the sample. The temperature was established in a range of -20 to $150^{\circ} \mathrm{C}$ with a heating ramp of $10^{\circ} \mathrm{C} / \mathrm{min}$. The data were analyzed with the universal analysis software provided together with the DSC instrument.

\subsection{Infrared Spectroscopy (IR)}

The individual compounds and the lyophilized CSNC were examined by spectroscopy on an IR spectrum (PerkinElmer Spectrum 400 IR, Waltham, MA, USA). Samples with minimum moisture content were placed in the prism for further analysis. The spectra were obtained with a range of 500 to $4000 \mathrm{~cm}^{-1}$ with a resolution of $1 \mathrm{~cm}^{-1}$ at $25^{\circ} \mathrm{C}$. The reference was a spectrum of ambient according to the methodology proposed by [31].

\subsection{Diffuse Reflectance}

The stability of the TEO-CSNC was determined with a Turbiscan MA2000 (Formulaction, Toulouse, France). The suspensions ( $5 \mathrm{~mL}$ ) were transferred to a cylindrical flat glass sample cell for measurement. The samples destabilization was analyzed using transmission and backscattering profiles by applying pulses from an infrared light source at $880 \mathrm{~nm}$ every $8 \mathrm{~min}$ for $24 \mathrm{~h}$, performing the measurement every 7 days, for 5 weeks, having two synchronous detectors: a transmission detector and a detector backscatter. The transmission detector will receive the light that moves through the sample (at $0^{\circ}$ of the incident beam), while the backscatter detector will receive the light that is dispersed backwards through the sample (at $135^{\circ}$ of the incident beam) [32]. The samples were analyzed at $25^{\circ} \mathrm{C}$.

\subsection{Antioxidant Capacity \\ 3.10.1. ABTS}

The antioxidant capacity by ABTS (2,2'-azino-bis- (3-ethylbenzthiazoline)-6-sulfonic acid) was determined by the methodology proposed by $[30,33]$. The ABTS radical cation stock solution was prepared to mix potassium persulfate solution and ABTS solution at $7 \mathrm{mmol}$ and $2.45 \mathrm{mmol}$. The mixture was kept in dark at $25^{\circ} \mathrm{C}$ for $16 \mathrm{~h}$ before its use. The working ABTS solution was obtained by dilution in phosphate buffer of $\mathrm{pH} 7.4$ of the stock solution to achieve an absorbance value of $0.7( \pm 0.02)$ at $734 \mathrm{~nm}$. A sample aliquot $(100 \mu \mathrm{L})$ was added to the ABTS $(2.9 \mathrm{~mL})$ working solution. Absorbance was measured using a BioSpectrometer ${ }^{\circledR}$ (Eppendorf AG, 22331, Hamburg, Germany) at $734 \mathrm{~nm}$ after $6 \mathrm{~min}$. For the antioxidant capacity assay (ABTS) a standard reference curve was constructed by plotting absorbance values against concentrations of 100-1000 $\mu \mathrm{mol}$ of ascorbic acid. The analysis was done in triplicate at $25^{\circ} \mathrm{C}$. 


\subsubsection{DPPH}

The kidnapping capacity of DPPH (2,2-diphenyl-1-picrylhydracil) was determined by the methodology proposed by [30,34]. Briefly, a solution containing $100 \mu \mathrm{mol}$ of DPPH (in methanol) was prepared. An aliquot of sample $(100 \mu \mathrm{L})$ was mixed with DPPH solution $(2.9 \mathrm{~mL})$ in methanol. The mixture was vigorously stirred and incubated at $25^{\circ} \mathrm{C}$ for $30 \mathrm{~min}$ in the dark. The absorbance was measured at $517 \mathrm{~nm}$ in a BioSpectrometer ${ }^{\circledR}$ (Eppendorf AG, 22331, Hamburg, Germany). The antioxidant capacity assay (DPPH) a standard reference curve was constructed by plotting absorbance values against concentrations of $100-1000 \mu \mathrm{mol}$ of ascorbic acid. The analysis was done in triplicate at $25^{\circ} \mathrm{C}$.

\subsubsection{FRAP}

The antioxidant capacity of TEO-CSNC was evaluated by its iron reduction capacity (FRAP assay), according to the method described by [30,35]. An aliquot of TEO-CSNC $(100 \mu \mathrm{L})$ was incubated in triplicate with FRAP reagent (containing 2,4,6-tri (2-pyridyl)s-triazine and $\left.\mathrm{FeCl}_{3}\right)$ and distilled water at $37^{\circ} \mathrm{C}(2.9 \mathrm{~mL})$. The absorbance values were read at $595 \mathrm{~nm}$ on a BioSpectrometer ${ }^{\circledR}$ (Eppendorf AG, 22331, Hamburg, Germany) after $30 \mathrm{~min}$. A control without a sample was prepared. For the antioxidant capacity assays (FRAP) a standard reference curve was constructed by plotting absorbance values against concentrations of 100-1000 $\mu \mathrm{mol}$ of ascorbic acid. The analysis was done in triplicate at $25{ }^{\circ} \mathrm{C}$.

\subsection{Essential Oil Content}

A Perkin Elmer gas chromatography (GC) Clarus 600 (Perkin Elmer, Inc., Waltham, MA, USA) with an Elite- 5 MS column $(30 \mathrm{~m} \times 0.32 \mathrm{~mm} \times 0.25 \mu \mathrm{m})$ equipped with a PerkinElmer Clarus $600 \mathrm{~T}$ mass spectrometer (MS) (Perkin Elmer, Inc., Waltham, Massachusetts, USA) with TurboMass 5.4.2 software was used. About $3 \mu \mathrm{L}$ of the solution was injected, and the system was run with helium as carrier gas with a column flow of $1 \mathrm{~mL} / \mathrm{min}$. The oven was programmed to start at $50{ }^{\circ} \mathrm{C}$. It was held at $50{ }^{\circ} \mathrm{C}$ for $5 \mathrm{~min}$ and then heated at $8{ }^{\circ} \mathrm{C} / \mathrm{min}$ to a final temperature of $180^{\circ} \mathrm{C}$ and kept for $5 \mathrm{~min}$. Mass spectra were recorded under electron ionization $(70 \mathrm{eV})$ with the $\mathrm{m} / \mathrm{z}$ range: $40-550 \mathrm{au}$. Peak identification was carried out with the mass spectral library.

\subsection{Statically Analysis}

To carry out the comparison of results concerning the treatments and as a function of time, an analysis of variance (ANOVA) was performed to evaluate the significant differences $(\alpha=0.05)$ between the independent variables (temperature and storage time). All the experiments were carried out considering three replicates and in random order. All statistical analyzes were performed using the Minitab statistical program (Minitab ${ }^{\circledR}$ Statistical Software 19 Inc., Centre, PA, USA).

\section{Conclusions}

The infrared spectroscopy and differential scanning calorimetry characterization revealed the excellent integration of components in the nanocapsules of thyme essential oil, and scanning electron microscopy evidenced nanocapsule spherical structure. The nanocapsules of thyme essential oil prepared by ionic gelation showed good stability to storage after 5 weeks of storage at 4 and $25^{\circ} \mathrm{C}$, the lower residual content of thyme essential oil was at $25^{\circ} \mathrm{C}$. The release mechanism was Fickian according to Korsmery-Peppas with an " $n$ " value of 0.193 , and the Higuchi model was the one that best described the release of thyme essential oil from chitosan nanocapsules, thus, accepting the hypothesis raised in the present experimental work. The antioxidant capacity of nanocapsule of thyme essential oil confirms the active agent's-controlled release in the aqueous medium, supported by the obtained values of zeta potential, the residual content of essential oil, and the release kinetics characteristic. Besides, the nanostructured systems obtained can be used without problems in the formulation and processing of foods. 
Author Contributions: R.M.G.-R.: investigation, methodology, formal analysis, writing-original draft. H.H.-S.: supervision, writing-review and editing. D.Q.-G.: proposal methodology, and supervision of release kinetic. L.A.-B.: investigation and methodology. Y.C.-N.: investigation, methodology and M.L.Z.-Z.: conceptualization, writing-review and editing, project administration, funding acquisition, moreover, approval final document. All authors have read and agreed to the published version of the manuscript.

Funding: The authors acknowledge the financial support to the projects PAPIIT IN222520 of DAGAPA-UNAM, Investigation Internal Project-FESC UNAM PIAPI2060.

Data Availability Statement: Not applicable.

Acknowledgments: Ricardo Moisés González-Reza is grateful for the doctoral scholarship support to CONACYT-México (702874). The authors also thank M.I. Alicia del Real López for her assistance in the SEM imaging process.

Conflicts of Interest: The authors declare no conflict of interest.

\section{References}

1. Aziz, Z.A.A.; Mohd-Nasir, H.; Ahmad, A.; Siti, S.H.; Peng, W.L.; Chuo, S.C.; Khatoon, A.; Umar, K.; Yaqoob, A.A.; Mohamad Ibrahim, M.N. Role of Nanotechnology for Design and Development of Cosmeceutical: Application in Makeup and Skin Care. Front. Chem. 2019, 7, 1-15. [CrossRef] [PubMed]

2. Crucho, C.I.C.; Barros, M.T. Polymeric nanoparticles: A study on the preparation variables and characterization methods. Mater. Sci. Eng. C 2017, 80, 771-784. [CrossRef]

3. Mora-Huertas, C.E.; Fessi, H.; Elaissari, A. Polymer-based nanocapsules for drug delivery. Int. J. Pharm. 2010, $385,113-142$. [CrossRef] [PubMed]

4. González-Reza, R.M.; Zambrano-Zaragoza, M.L.; Hernández-Sánchez, H. Polymeric Nanoparticles in Foods. In Plant Nanobionics. Nanotechnology in the Life Sciences; Springer: Berlin/Heidelberg, Germany, 2019; pp. 217-233.

5. Klein, M.; Poverenov, E. Natural biopolymer-based hydrogels for use in food and agriculture. J. Sci. Food Agric. 2020, 100, 2337-2347. [CrossRef]

6. Branca, C.; Khouzami, K.; Wanderlingh, U.; D'Angelo, G. Effect of intercalated chitosan/clay nanostructures on concentrated pluronic F127 solution: A FTIR-ATR, DSC and rheological study. J. Colloid Interface Sci. 2018, 517, 221-229. [CrossRef] [PubMed]

7. Liu, J.; Meng, C.G.; Liu, S.; Kan, J.; Jin, C.H. Preparation and characterization of protocatechuic acid grafted chitosan films with antioxidant activity. Food Hydrocoll. 2017, 63, 457-466. [CrossRef]

8. Bakkali, F.; Averbeck, S.; Averbeck, D.; Idaomar, M. Biological effects of essential oils-A review. Food Chem. Toxicol. 2008, 46, 446-475. [CrossRef]

9. Ryu, V.; McClements, D.J.; Corradini, M.G.; McLandsborough, L. Effect of ripening inhibitor type on formation, stability, and antimicrobial activity of thyme oil nanoemulsion. Food Chem. 2018, 245, 104-111. [CrossRef]

10. Rezaei, A.; Fathi, M.; Jafari, S.M. Nanoencapsulation of hydrophobic and low-soluble food bioactive compounds within different nanocarriers. Food Hydrocoll. 2019, 88, 146-162. [CrossRef]

11. Delshadi, R.; Bahrami, A.; Tafti, A.G.; Barba, F.J.; Williams, L.L. Micro and nano-encapsulation of vegetable and essential oils to develop functional food products with improved nutritional profiles. Trends Food Sci. Technol. 2020, 104, 72-83. [CrossRef]

12. Prakash, B.; Kujur, A.; Yadav, A.; Kumar, A.; Singh, P.P.; Dubey, N.K. Nanoencapsulation: An efficient technology to boost the antimicrobial potential of plant essential oils in food system. Food Control 2018, 89, 1-11. [CrossRef]

13. Correa-Pacheco, Z.N.; Bautista-Baños, S.; Valle-Marquina, M.Á.; Hernández-López, M. The Effect of Nanostructured Chitosan and Chitosan-thyme Essential Oil Coatings on Colletotrichum gloeosporioides Growth in vitro and on cv Hass Avocado and Fruit Quality. J. Phytopathol. 2017, 165, 297-305. [CrossRef]

14. Sedlaříková, J.; Janalíková, M.; Rudolf, O.; Pavlačková, J.; Egner, P.; Peer, P.; Varad'ová, V.; Krejčí, J. Chitosan/thyme oil systems as affected by stabilizing agent: Physical and antimicrobial properties. Coatings 2019, 9, 165. [CrossRef]

15. Ghaderi Ghahfarokhi, M.; Barzegar, M.; Sahari, M.A.; Azizi, M.H. Enhancement of thermal stability and antioxidant activity of thyme essential oil by encapsulation in Chitosan Nanoparticles. J. Agric. Sci. Technol. 2016, 18, 1781-1792.

16. Wu, L.; Zhang, J.; Watanabe, W. Physical and chemical stability of drug nanoparticles. Adv. Drug Deliv. Rev. 2011, 63, 456-469. [CrossRef] [PubMed]

17. Asprea, M.; Leto, I.; Bergonzi, M.C.; Bilia, A.R. Thyme essential oil loaded in nanocochleates: Encapsulation efficiency, in vitro release study and antioxidant activity. LWT_Food Sci. Technol. 2017, 77, 497-502. [CrossRef]

18. Sotelo-Boyás, M.; Correa-Pacheco, Z.; Bautista-Baños, S.; Gómez y Gómez, Y. Release study and inhibitory activity of thyme essential oil-loaded chitosan nanoparticles and nanocapsules against foodborne bacteria. Int. J. Biol. Macromol. 2017, 103, 409-414. [CrossRef]

19. Soares, P.I.P.; Sousa, A.I.; Silva, J.C.; Ferreira, I.M.M.; Novo, C.M.M.; Borges, J.P. Chitosan-based nanoparticles as drug delivery systems for doxorubicin: Optimization and modelling. Carbohydr. Polym. 2016, 147, 304-312. [CrossRef] 
20. Sotelo-Boyás, M.E.; Correa-Pacheco, Z.N.; Bautista-Baños, S.; Corona-Rangel, M.L. Physicochemical characterization of chitosan nanoparticles and nanocapsules incorporated with lime essential oil and their antibacterial activity against food-borne pathogens. LWT-Food Sci. Technol. 2017, 77, 15-20. [CrossRef]

21. Hasheminejad, N.; Khodaiyan, F.; Safari, M. Improving the antifungal activity of clove essential oil encapsulated by chitosan nanoparticles. Food Chem. 2018, 275, 113-122. [CrossRef]

22. Matshetshe, K.I.; Parani, S.; Manki, S.M.; Oluwafemi, O.S. Preparation, characterization and in vitro release study of $\beta$ cyclodextrin/chitosan nanoparticles loaded Cinnamomum zeylanicum essential oil. Int. J. Biol. Macromol. 2018, 118, 676-682. [CrossRef] [PubMed]

23. Shao, Y.; Wu, C.; Wu, T.; Li, Y.; Chen, S.; Yuan, C.; Hu, Y. Eugenol-chitosan nanoemulsions by ultrasound-mediated emulsification: Formulation, characterization and antimicrobial activity. Carbohydr. Polym. 2018, 193, 144-152. [CrossRef] [PubMed]

24. Ignatova, M.; Manolova, N.; Rashkov, I.; Markova, N. Quaternized chitosan/k-carrageenan/caffeic acid-coated poly(3hydroxybutyrate) fibrous materials: Preparation, antibacterial and antioxidant activity. Int. J. Pharm. 2016, 513, 528-537. [CrossRef]

25. Aljawish, A.; Muniglia, L.; Klouj, A.; Jasniewski, J.; Scher, J.; Desobry, S. Characterization of films based on enzymatically modified chitosan derivatives with phenol compounds. Food Hydrocoll. 2016, 60, 551-558. [CrossRef]

26. Sekar, V.; Rajendran, K.; Vallinayagam, S.; Deepak, V.; Mahadevan, S. Synthesis and characterization of chitosan ascorbate nanoparticles for therapeutic inhibition for cervical cancer and their in silico modeling. J. Ind. Eng. Chem. 2018, 62, 239-249. [CrossRef]

27. Kadam, D.; Lele, S.S. Cross-linking effect of polyphenolic extracts of Lepidium sativum seedcake on physicochemical properties of chitosan films. Int. J. Biol. Macromol. 2018, 114, 1240-1247. [CrossRef] [PubMed]

28. Zambrano-Zaragoza, M.L.; Mercado-Silva, E.; Del Real, L.A.; Gutiérrez-Cortez, E.; Cornejo-Villegas, M.A.; Quintanar-Guerrero, D. The effect of nano-coatings with $\alpha$-tocopherol and xanthan gum on shelf-life and browning index of fresh-cut "Red Delicious" apples. Innov. Food Sci. Emerg. Technol. 2014, 22, 188-196. [CrossRef]

29. González-Reza, R.M.; Quintanar-Guerrero, D.; Flores-Minutti, J.J.; Gutiérrez-Cortez, E.; Zambrano-Zaragoza, M.L. Nanocapsules of $\beta$-carotene: Thermal degradation kinetics in a scraped surface heat exchanger (SSHE). LWT-Food Sci. Technol. 2015, 60, 124-130. [CrossRef]

30. González-Reza, R.M.; Hernandez-Sanchez, H.; Zambrano-Zaragoza, M.L.; Gutierrez-Lopez, G.F.; Del Real, A.; QuintanarGuerrero, D.; Velasco-Bejarano, B. Influence of Stabilizing and Encapsulating Polymers on Antioxidant Capacity, Stability, and Kinetic Release of Thyme Essential Oil Nanocapsules. Foods 2020, 9, 1884. [CrossRef]

31. Miranda-Linares, V.; Quintanar-Guerrero, D.; Del Real, A.; Zambrano-Zaragoza, M.L. Spray-drying method for the encapsulation of a functionalized ingredient in alginate-pectin nano- and microparticles loaded with distinct natural actives: Stability and antioxidant effect. Food Hydrocoll. 2020, 101. [CrossRef]

32. González-Reza, R.M.; Quintanar-Guerrero, D.; Del Real-López, A.; Piñon-Segundo, E.; Zambrano-Zaragoza, M.L. Effect of sucrose concentration and $\mathrm{pH}$ onto the physical stability of $\beta$-carotene nanocapsules. LWT-Food Sci. Technol. 2018, 90, 354-361. [CrossRef]

33. Re, R.; Pellegrini, N.; Proteggente, A.; Pannala, A.; Yang, M.; Rice-Evans, C. Antioxidant Activity Applying An Improved Abts Radical. Free Radic. Biol. Med. 1999, 26, 1231-1237. [CrossRef]

34. Brand-Williams, W.; Cuvelier, M.E.; Berset, C. Use of a free radical method to evaluate antioxidant activity. LWT-Food Sci. Technol. 1995, 28, 25-30. [CrossRef]

35. Benzie, I.F.F.; Strain, J.J. The ferric reducing ability of plasma (FRAP) as a measure of "antioxidant power": The FRAP assay. Anal. Biochem. 1996, 239, 70-76. [CrossRef] 